\title{
Anaphylaxis with Latrodectus Antivenin Resulting in Cardiac Arrest
}

\author{
Christine M. Murphy • Jeannie J. Hong • \\ Michael C. Beuhler
}

Published online: 4 November 2011

(C) American College of Medical Toxicology 2011

\begin{abstract}
Latrodectus mactans antivenin is a safe and effective therapy for severe black widow spider envenomations when given to most patients. We report a case of a 37-year-old male with a history of asthma that was given L. mactans antivenin for symptoms related to a black widow envenomation and developed a severe anaphylactic reaction resulting in cardiac arrest. When traditional therapies failed, the patient was given methylene blue for anaphylactic shock resulting in a 30 -h period of hemodynamic stability. Despite initial resuscitation, the patient ultimately died $40 \mathrm{~h}$ after presentation. Under the right circumstances, L. mactans antivenin remains a safe and effective therapy for severe black widow envenomations. However, anaphylaxis is a risk for those receiving this therapy, even when the antivenin is diluted and given as an infusion. We report the first death related to diluted L. mactans antivenin given as an infusion.
\end{abstract}

Keywords Black widow - Antivenin · Anaphylaxis · Methylene blue $\cdot$ Latrodectus mactans

C. M. Murphy $(\bowtie)$

Department of Emergency Medicine, Carolinas Medical Center, PO Box 32861, MEB 3rd Floor,

Charlotte, NC 28232, USA

e-mail: christine.murphy@carolinas.org

J. J. Hong

School of Pharmacy, University of North Carolina,

Chapel Hill, NC, USA

M. C. Beuhler

Carolinas Poison Center,

Charlotte, NC, USA

\section{Introduction}

Black widow envenomations are common but rarely fatal in the USA. On review of the last 11 years of published poison center data, there were an average of 2,500 bites per year with no reported fatalities [1-11]. Mainstays of therapy include opioids, muscle relaxants, and Latrodectus mactans antivenin. On query of reported cases to the National Poisoning Data System of all human envenomations from L. mactans between 2000 and 2009, there were 25,702 reported envenomations of which 554 $(2.16 \%)$ received L. mactans antivenin [personal communication with Dr. A Bronstein, August 2011]. The antivenin is very effective at improving symptoms related to the envenomation. The biggest complication with administration of antivenin is anaphylaxis, as it is comprised from partially purified horse serum. When it occurs, L. mactans antivenin-induced anaphylaxis usually responds to traditional therapies: steroids, epinephrine, and antihistamines. To date, only one L. mactans antivenin-associated death has been previously reported in the literature [12]. In this case, the patient had a severe anaphylactic reaction resulting from the administration of undiluted $L$. mactans antivenin given as an intravenous bolus [12].

\section{Case Report}

A 37-year-old male presented to an emergency department $3 \mathrm{~h}$ after sustaining a self-confirmed black widow spider bite to the right lower extremity. Approximately $1 \mathrm{~h}$ later, he developed tightening in his neck and shoulders that was associated with some nausea and diaphoresis. His only medical history was asthma, and he used an albuterol 
metered-dose inhaler and fluticasone propionate/salmeterol inhalation powder, as needed.

Initial vital signs were temperature of $98.5^{\circ} \mathrm{F}$, blood pressure of $159 / 74 \mathrm{mmHg}$, pulse ox $96 \%$ on room air, respiratory rate of 22 respirations per minute, and heart rate of 103 beats per minute. Physical exam demonstrated a man in moderate distress with a small area of raised erythema on his right anterior mid-shin. He had no diaphoresis and his abdomen was soft and non-tender with no peritoneal signs.

Symptomatic relief was attempted, but not achieved, with one intravenous (IV) dose of $30 \mathrm{mg}$ ketorolac and two IV doses of both $1 \mathrm{mg}$ lorazepam and $1 \mathrm{mg}$ hydromorphone. The patient was given a subcutaneous test dose of normal horse serum in saline, as directed by $L$. mactans antivenin package insert, with no reaction. An infusion of $2.5 \mathrm{~mL}$ of antivenin in $50 \mathrm{~mL}$ of $0.9 \%$ normal saline was started. Five minutes after the antivenin infusion was started (10\% infused), he developed symptoms of anxiety, facial tingling, shortness of breath, tachycardia to 135 beats per minute, and tachypnea to 36 breaths per minute with a decrease in his oxygen saturation to $89 \%$ on room air. The antivenin infusion was stopped, but cardiac arrest occurred within 3 min.

He was intubated, given multiple doses of epinephrine, as well as diphenhydramine, naloxone, and methylprednisolone. Nebulized albuterol was administered when he became difficult to ventilate manually and wheezing was noted. Thirty minutes after arrest, the patient had return of spontaneous circulation (ROSC). He was started on a dopamine infusion for persistent hypotension and quickly exceeded maximum dosing ( $30 \mu \mathrm{g} / \mathrm{kg} / \mathrm{min})$. Subsequently, phenylephrine was started and rapidly increased to $126 \mu \mathrm{g} / \mathrm{min}$. The patient went into cardiac arrest for a second time and standard ACLS therapies were performed, including administration of calcium chloride and sodium bicarbonate. The patient had ROSC 20 min later and made purposeful movements. Arterial blood gas (ABG) 20 min after ROSC demonstrated acidosis ( $\mathrm{pH}$ 6.934) and carbon dioxide retention (pCO2, $86.8 \mathrm{mmHg}$ ) (Fig. 1). He was given fentanyl and vecuronium to resedate and paralyze him and was transferred to a tertiary care center. Despite being on high doses of phenylephrine, vasopressin, dopamine, norepinephrine, and epinephrine drips, he remained hypotensive with blood pressures ranging from $84 / 75$ to $104 / 89 \mathrm{mmHg}$ (Table 1). He continued to have myoclonic jerking of shoulders, neck and arms, his pupils were fixed and dilated, and he developed oliguria. ABG demonstrated continued acidosis $(\mathrm{pH}$ 6.931) and carbon dioxide retention ( $\mathrm{pCO} 2$, $100 \mathrm{mmHg}$ ) despite a ventilator rate of 25 . A bolus dose of $1 \mathrm{mg} / \mathrm{kg}$ of methylene blue was given intravenously. Within $45 \mathrm{~min}$, the dopamine, phenylephrine, norepinephrine were discontinued and the epinephrine decreased to $2.6 \mu \mathrm{g} / \mathrm{kg} /$ min. Epinephrine and vasopressin were discontinued within $85 \mathrm{~min}$ of the methylene blue bolus, and $\mathrm{ABG}$ also demonstrated improved respiratory function with $\mathrm{pH}$ of 7.119 and pCO2 of $44.1 \mathrm{mmHg}$. The patient improved significantly over the next $12 \mathrm{~h}$ and was noted to be following commands and attempting to get out of bed while still intubated. The primary physician reported the patient "seemed to have avoided major anoxic brain injury; serial labs have shown improvement in academia but metabolic acidosis still significant enough to preclude extubation. We should be able to extubate him tomorrow."

During the night of hospital day 2, the patient developed a temperature of $101.6^{\circ} \mathrm{F}$, his blood pressure dropped from $121 / 83$ to $54 / 35 \mathrm{mmHg}$, and his oxygen saturation abruptly decreased to $80 \%$ with an $\mathrm{FiO} 2$ of $45 \%$. A venous blood gas was performed while manually ventilating the patient $\mathrm{pH} 6.99, \mathrm{pCO} 2$ of $71 \mathrm{mmHg}, \mathrm{pO} 2$ of $10 \mathrm{mmHg}$, and oxygen saturation of $5 \%$. Thirty minutes later, he was restarted on norepinepherine, went into cardiac arrest and expired approximately $40 \mathrm{~h}$ after initial presentation.

An autopsy was not performed. The medical examiner attributed the cause of death to anaphylactic shock secondary to administration of antivenin based on review of the medical record and external viewing only. No angioedema or rashes were noted in the medical examiner's report. Given the clinical course and that deep vein thrombosis prophylaxis was intentionally withheld, it is more likely the patient died of a pulmonary embolism as a complication from his antivenin-induced anaphylactic shock and cardiac arrest. His marked and sustained improvement for $30 \mathrm{~h}$ followed by his sudden death without recurrence of anaphylactic symptoms supports this.

\section{Discussion}

Black widow spiders, L. mactans, are native to North America, and symptoms related to their bites are caused by the venom component, $\alpha$-latrotoxin [12]. Alpha-latrotoxin binds to presynaptic receptors neurexin I- $\alpha$ and latrophilin initiating a cascade of events that leads to neurotransmitter release from the presynaptic nerve into the synapse. The result is excessive motor end plate stimulation [13]. Some of the resulting clinical effects include muscle spasm, localized diaphoresis, piloerection, and hypertension [14]. Bites usually occur on an extremity and may or may not be accompanied by a stinging sensation. A period of 10 60 min may pass before other symptoms develop [15-17]. Shoulder, back, chest, and abdominal pain often develop as the venom effect moves proximal to the bite site. There may be a marked feeling of restlessness, but intractable pain is the major complaint of Latrodectus-envenomated patients. The majority of symptoms peak during the first $48 \mathrm{~h}$ after envenomation and decline within 2-3 days. Symptoms may persist up to 7 days; however, generalized 
Fig. 1 Blood gas values vs. time after presentation. All values are from arterial blood gases with the exception of values at hour 39 which are from a venous blood gas. Solid arrows indicate active cardiac arrest; open arrow indicates time of methylene blue administration

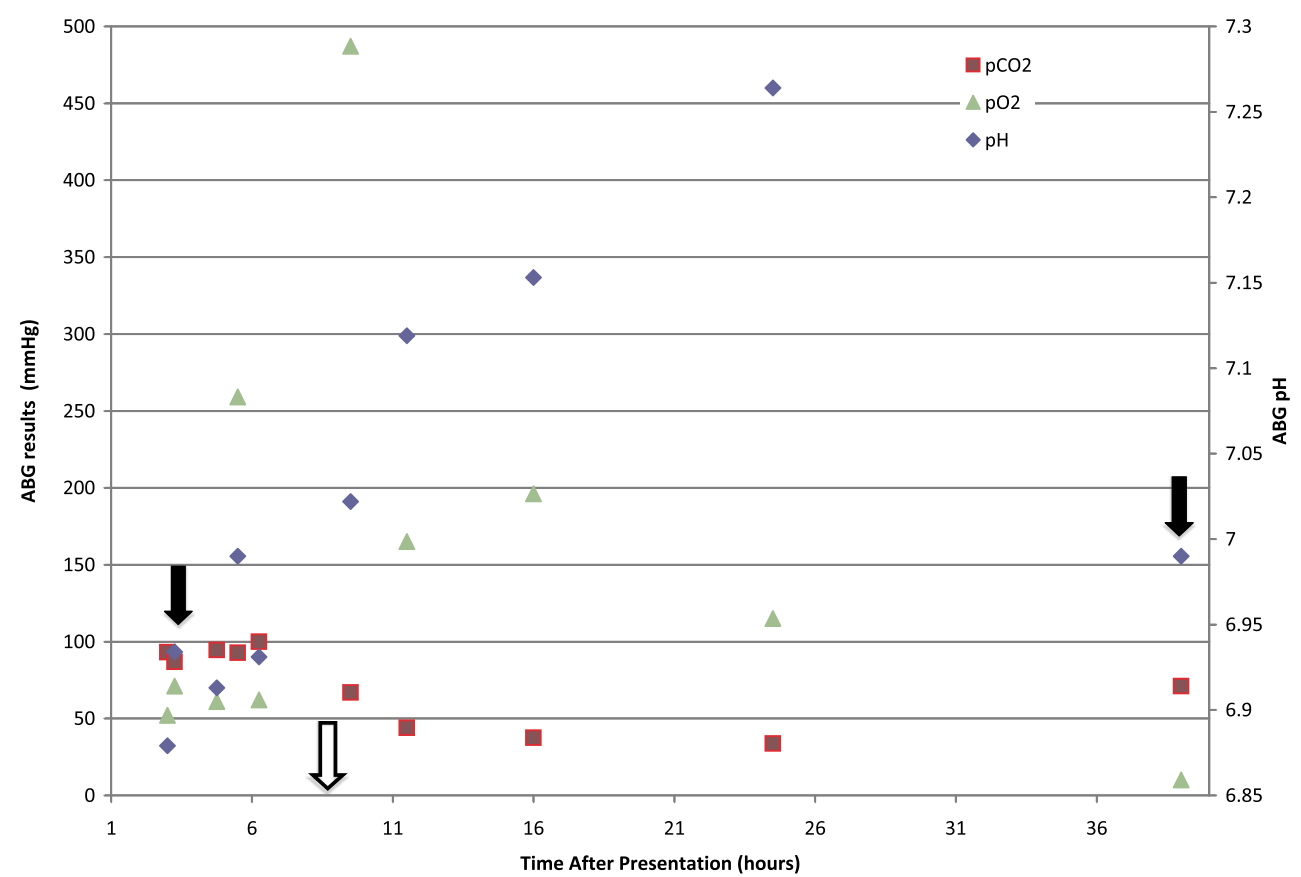

weakness, muscle pain, and malaise may last for weeks [12, 16-19]. A grading scale has been developed to assist assessment of symptom severity (Table 2) [20].

Although several treatment regimens have been used, parenteral opioids and L. mactans antivenin (Antivenin ${ }^{\circledR}$; Merck \& Co., Inc, Whitehouse Station, NJ, USA) are most successful in treating the signs and symptoms of severe Latrodectus envenomation. L. mactans antivenin alone was found to shorten the course of illness for severely envenomated patients (grades 2 and 3) when compared to opioids in a retrospective study by Clark and colleagues [20]. L. mactans antivenin is very effective at relieving acute pain and resolving systemic symptoms, and its administration up to $90 \mathrm{~h}$ post-envenomation has been associated with clinical resolution of symptoms [21, 22]. Current recommendations for when to give antivenin

Table 1 Vasopressor use at given time points after presentation

\begin{tabular}{ll}
\hline Time after presentation (hours) & Medication and dose given \\
\hline 9.5 & $\begin{array}{l}\text { Norepinephrine } 10 \mu \mathrm{g} / \mathrm{kg} / \mathrm{min} \\
\text { Phenylephrine } 70 \mu \mathrm{g} / \mathrm{min}\end{array}$ \\
& Epinephrine $11 \mu \mathrm{g} / \mathrm{min}$ \\
& Dopamine $12 \mu \mathrm{g} / \mathrm{kg} / \mathrm{min}$ \\
& Vasopressin $0.04 \mathrm{units} / \mathrm{minute}$ \\
& Methylene blue $1 \mathrm{mg} / \mathrm{kg}$ bolus \\
9.75 & All vasopressors continued as \\
& noted above \\
& Vasopressin $0.04 \mathrm{U} / \mathrm{min}$ \\
10.5 & Epinephrine $2.6 \mu \mathrm{g} / \mathrm{min}$ \\
& All vasopressors off \\
\hline
\end{tabular}

include grades 2 or 3 envenomations, envenomations refractory to opiates and sedative hypnotics, patients suffering from rare effects such as priapism, and pregnant patients at risk for miscarriage due to latrodectism-related muscle cramping and hypertension [15, 23, 24]. However, a recently published review found no change in fetal outcome in pregnant women whose treatment included black widow spider antivenin and those who were treated with other medications calling this last indication into question [25]. Some early sources, including the L. mactans antivenin package insert, recommend giving this therapy to all envenomated patients at the extremes of age $[15,23,26]$. The only contraindication listed is an existing horse allergy or previous exposure to horse serum [23]. Interestingly, both our patient and the L. mactans antivenin-related death reported by Clark had medical histories of asthma [12, 23].

Antivenins are hyperimmune sera containing antibodies, usually $\operatorname{IgG}$, collected from animals after inoculation with a target venom. L. mactans antivenin is a partially purified equine-derived $\mathrm{IgG}$ used to treat envenomations from multiple Latrodectus species due to similarities in venoms [27]. Acute hypersensitivity reactions occur with exposure to animal proteins and whole immunoglobulins within the antivenin. Most of the data used to determine the risk for developing hypersensitivity reactions to $L$. mactans antivenin is extrapolated from experience with another horse serum-based antivenin, Antivenin Crotalidae Polyvalent (ACP; Wyeth Laboratories, Philadelphia, PA, USA). Reports indicate that $10-39 \%$ of patients receiving ACP developed immediate hypersensitivity reactions [28, 29]. As the overall amount of ACP used to neutralize snake venom is much larger than the amount of $L$. 
Table 2 Severity grading scale for Latrodectus mactans envenomation. Adapted from Clark et al. [20] and Hoover and Fortenberry JD [24]

\begin{tabular}{ll}
\hline $\begin{array}{l}\text { Grade of } \\
\text { envenomation }\end{array}$ & Signs and symptoms \\
\hline 1 Mild & Normal vital signs \\
& Asymptomatic \\
& Local pain at envenomation site \\
& Normal vital signs \\
& Muscular pain in envenomated extremity \\
& Extension of muscular pain to abdomen if \\
& envenomated on lower extremity or chest if \\
& envenomated on upper extremity \\
& Local diaphoresis of envenomation site or \\
& involved extremity \\
& Abnormal vital signs \\
& Hypertension (systolic blood pressure \\
& $>140$ mmHg or diastolic blood pressure \\
& $>90$ mmHg) \\
& Tachycardia (pulse $>100)$ \\
Generalized muscular pain in back, & abdomen, and chest \\
Diaphoresis remote from envenomation site & Nausea and vomiting \\
Headache & Rare effects such as priapism \\
&
\end{tabular}

mactans antivenin used to neutralize black widow spider venom, the use of ACP data to predict the rate of anaphylaxis and immediate hypersensitivity may overestimate the frequency of these events. However, anaphylaxis remains the most severe complication of L. mactans antivenin.

To determine which patients may develop hypersensitivity to antivenin, skin testing is often implemented prior to antivenin administration in the USA and is recommended by the L. mactans antivenin manufacturer $[14,23]$. However, several studies have reported the inaccurate prediction of the skin testing and challenged the usefulness of this practice. In one study of 25 patients from Nigeria and Thailand, $12(48 \%)$ had negative skin and conjunctival tests, yet developed anaphylactic reactions when treated with equine-derived snake antivenoms [30]. All 23 patients receiving ACP in the case review by White and Weber had negative skin testing, but despite this, $13(56 \%)$ developed "adverse reactions to antivenin" [29]. In an additional report, four of five patients (80\%) who responded "unfavorably" to intravenous ACP had negative skin tests [31]. As it is unreliable and delays treatment, we believe skin testing should be abandoned.

The best method of minimizing the risk and severity of immediate hypersensitivity may be administration of diluted antivenin by means of a slow infusion. Rapid infusion has been associated with an increased number of patients experiencing flushing, nausea, or anxiety [31]. Additionally, in the only other previously reported case of death related to L. mactans antivenin administration, undiluted antivenin was given as a bolus dose over a very short period of time [12]. Rapid administration of the antivenin may induce a massive histamine release causing anaphylactic signs and symptoms in patients [20]. Although severe reactions may not be prevented by slower infusion, this may limit the immediate anaphylactoid hypersensitivity reactions. Based on their experience, both Clark et al. and Merck recommend diluting the antivenin with $50-100 \mathrm{~mL}$ of normal saline or $5 \%$ dextrose (Clark et al.) or $10-50 \mathrm{~mL}$ of normal saline (Merck) and infusing the reconstituted solution over 15-30 $\min [12,20,23]$. Pre-medication with antihistamines, steroids, or epinephrine has not been shown to prevent or decrease the frequency of these reactions. When anaphylaxis does occur, the infusion should be stopped immediately and patients should be treated with standard therapies: antihistamines, steroids, and epinephrine. Based on our experience with this case and a review of the literature, we would also recommend consideration of using methylene blue if standard therapies fail to reverse anaphylactic shock.

Methylene blue has been used over the last several years as a treatment for intractable hypotension in anaphylaxis, sepsis, and vasoplegia from cardiopulmonary bypass during cardiac surgery [32-35]. Multiple case reports document the reversal of anaphylactic symptoms, including druginduced cardiac arrest and angioedema, after patients receive methylene blue [36-38]. Methylene blue inhibits soluble guanylyl cyclase, preventing vasodilation and decreasing associated vascular permeability by limiting the effect of nitric oxide [32,36]. Evora and several others report rapid improvement of several patients who failed standard therapy with epinephrine, antihistamines, and steroids after developing hypotension with or without associated angioedema [36-38]. Reactions were induced by a variety of agents including intravenous contrast dye, penicillin and unknown agents. A dosing of $1.5-2 \mathrm{mg} / \mathrm{kg}$ IV bolus was given followed by infusions of $1.5-2 \mathrm{mg} / \mathrm{kg} / \mathrm{hr}$ over 1-2 h [36-38]. Given our success along with others in treating anaphylactic shock with methylene blue, coupled with a rational biochemical mechanism for benefit, we believe methylene blue should be considered when standard treatments fail to reverse antivenin and possibly drug-induced anaphylaxis.

\section{Conclusion}

While L. mactans antivenin is very effective, physicians should be wary of using this antivenin without first exhausting traditional means of symptom control in patients 
with contraindications. Based on this case and the previously reported death, we would propose asthma should be a contraindication to receiving L. mactans antivenin. Additionally, this case reinforces that skin testing is not sufficient to exclude potential allergic reactions and should be abandoned. Although our patient eventually succumbed, the initial resuscitation was successful only after the addition of methylene blue, thus supporting the use of methylene blue in anaphylactic shock when standard therapies fail. To our knowledge, this is only the second death related to black widow antivenin reported in the literature, and it is the first reported death attributed to $L$. mactans antivenin when diluted and infused over an extended period of time.

\section{References}

1. Litovitz TL, Klein-Schwartz W, White S et al (2000) 1999 Annual Report of the American Association of Poison Control Centers Toxic Exposure Surveillance System. Am J Emerg Med 18(5):517-574

2. Litovitz TL, Klein-Schwartz W, White S et al (2001) 2000 Annual Report of the American Association of Poison Control Centers Toxic Exposure Surveillance System. Am J Emerg Med 19 (5):337-395

3. Litovitz TL, Klein-Schwartz W, Watson WA et al (2002) 2001 Annual Report of the American Association of Poison Control Centers Toxic Exposure Surveillance System. Am J Emerg Med 20(5):391-452

4. Watson WA, Litovitz TL, Rodgers GC et al (2003) 2002 Annual Report of the American Association of Poison Control Centers Toxic Exposure Surveillance System. Am J Emerg Med 21(5):353-421

5. Watson WA, Litovitz TL, Klein-Schwartz W et al (2004) 2003 Annual Report of the American Association of Poison Control Centers Toxic Exposure Surveillance System. Am J Emerg Med 22(5):335-404

6. Watson WA, Litovitz TL, Rodgers GC et al (2005) 2004 Annual Report of the American Association of Poison Control Centers Toxic Exposure Surveillance System. Am J Emerg Med 23(5):589-666

7. Lai MW, Klein-Schwartz W, Rodgers GC et al (2006) 2005 Annual Report of the American Association of Poison Control Centers' National Poisoning and Exposure Database. Clin Toxicol 44(6-7):803-932

8. Bronstein A, Spyker D, Cantilena L, Green J, Rumack B, Heard S (2007) 2006 Annual report of the American Association of Poison Control Centers' National Poison Data System (NPDS). Clin Toxicol 45(8):815-917

9. Bronstein A, Spyker D, Cantilena L, Green J, Rumack B, Heard S (2008) 2007 Annual report of the American Association of Poison Control Centers' National Poison Data System (NPDS): 25th Annual Report. Clin Toxicol 46(10):927-1057

10. Bronstein A, Spyker D, Cantilena L, Green J, Rumack B, Griffin S (2009) 2008 Annual report of the American Association of Poison Control Centers' National Poison Data System (NPDS): 26th Annual Report. Clin Toxicol 47(10):911-1084

11. Bronstein A, Spyker D, Cantilena L, Green J, Rumack B, Griffin S (2010) 2009 Annual report of the American Association of Poison Control Centers' National Poison Data System (NPDS): 27th Annual Report. Clin Toxicol 48(10):979-1178

12. Clark RF (2001) The safety and efficacy of antivenin Latrodectus mactans. Clin Toxicol 39(2):125-127
13. Baba A, Cooper JR (1980) The action of black widow spider venom on cholinergic mechanisms in synaptosomes. J Neurochem 34(6):1369-1379

14. Heard K, O'Malley GF, Dart RC (1999) Antivenom therapy in the Americas. Drugs 58(1):5-15

15. Rauber A (1983) Black widow spider bites. J Toxicol Clin Toxicol 21(4-5):473-485

16. Maretic Z, Stanic N (1954) The health problem of arachnidism. Bull World Health Organ 11:1007-1022

17. Bogen E (1926) Arachnidism: a study in spider poisoning. JAMA $86: 1894-1896$

18. Wiener S (1978) Red back spider bite in Australia: an analysis of red-back spider bites. Med J Aust 2:620-623

19. Rauber AP (1980) The case of the red widow: a review of latrodectism. Vet Hum Toxicol 22:39-41

20. Clark RF, Wethern-Kestner S, Vance MV, Gerkin R (1992) Clinical presentation and treatment of black widow spider envenomation: a review of 163 cases. Ann Emerg Med 21:782-787

21. Suntorntham S, Roberts JR, Nilsen GJ (1994) Dramatic clinical response to the delayed administration of black widow spider antivenin [letter]. Ann Emerg Med 24(6):1198-1199

22. O'Malley GF, Dart RC, Kuffner EF (1999) Successful treatment of latrodectism with antivenin after 90 hours. N Engl J Med 340:657

23. Antivenin ${ }^{\circledR}$ [package insert]. Whitehouse Station, NJ: Merck \& Co., Inc; 2005 Feb.

24. Hoover NG, Fortenberry JD (2004) Use of antivenin to treat priapism after a black widow spider bite. Pediatrics 114:e128-e129

25. Wolfe MD, Myers O, Caravati RWF, Seifert SA (2011) Black widow spider envenomation in pregnancy. J Matern Fetal Neonatal Med 24(1):122-126

26. Horn WP (1963) Arachnidism in the US. JAMA 185(11):839-843

27. McCrone JD, Netzloff ML (1965) An immunological and electrophoretical comparison of the venoms of the North American Lactrodectus spiders. Toxicon 3(2):107-110

28. Jurkovich GJ, Luterman A, McCullar K et al (1988) Complications of Crotalidae antivenin therapy. J Trauma 22:1032-1037

29. White RR, Weber RA (1991) Posionous snakebite in central Texas: possible indicators for antivenin treatment. Ann Surg 213 (5):466-471

30. Malasit P, Warrell DA, Chanthavanich P et al (1986) Prediction prevention and mechanism of early (anaphylactic) antivenom reactiosn in victims of snakebites. Br Med J 292:17-20

31. Corrigan P, Russeell FE, Wainschell J (1978) Clinical reactions to antivenin. In: Rosenberg P (ed) Toxins: animal, plant and microbial. Pergammon Press, Oxford, pp 457-465

32. Evora P, Viaro F (2006) The guanylyl cyclase inhibition by MB as vasoplegic circulatory shock therapeutical target. Curr Drug Targets 7:1195-1204

33. Kwok E, Howes D (2006) Use of methylene blue in sepsis: a systematic review. J Intensive Care Med 21:359-363

34. Maslow A et al (2006) The hemodynamic effects of methylene blue when administered at the onset of cardiopulmonary bypass. Anesth Analg 103:2-8

35. Dagenais F, Mathieu P (2003) Rescue therapy with methylene blue in systemic inflammatory response syndrome after cardiac surgery. Can J Cardiol 19(2):167-169

36. Evora P, Simon M (2007) Role of nitric oxide production in anaphylaxis and its relevance for the treatment of anaphylactic hypotension with methylene blue. Ann Allergy Asthma Immunol 99:306-313

37. Rodrigues J, Filho A, Rodrigues A, Vicente W, Evora P (2007) Methylene blue for clinical anaphylaxis treatment: a case report. Sao Paulo Med J 125(1):60-62

38. Oliveira Neto AM, Duarte NM, Vicente W, Viaro F, Evora P (2003) Methylene blue: an effective treatment for contrast medium-induced anaphylaxis. Med Sci Monit 9(11):CS102-CS106 